\title{
Ordenação e sequenciação de perguntas de leitura para o gênero poema no Ensino Fundamental
}

\author{
Rayllane de Souza Cruz \\ Universidade Federal do Tocantins \\ rayllanesc@hotmail.com \\ Ângela Francine Fuza \\ Universidade Federal do Tocantins \\ angelafuza@uft.edu.br \\ Renilson José Menegassi \\ Universidade Estadual de Maringá \\ renilson@wnet.com.br
}

\section{Resumo}

Este trabalho tem como objetivo elaborar uma proposta de ordenação e sequenciação de perguntas de leitura para o gênero poema, voltada ao Ensino Fundamental, com base na perspectiva de leitura como interação, contribuindo para a formação e o desenvolvimento do aluno-leitor. Para isso, o estudo fundamenta-se nas perspectivas sobre leitura, centrada nos estudos da Linguística Aplicada e da prática de ordenação e de sequenciação de leitura, discutida por Solé (1998) e ampliada por Menegassi $(2008$; 2010; 2016), Fuza e Menegassi $(2018$; 2017) e Fuza (2017), que ressaltam a necessidade dessa proposta como parte do processo de desenvolvimento do leitor na escola. Como resultado, observa-se que a ordenação e a sequenciação de perguntas de leitura para o gênero poema permitem ao aluno-leitor: (a) extrair significados e atribuir sentidos ao que lê; (b) posicionarse sobre a temática do texto; (c) produzir um texto como réplica.

Palavras-chave: Leitura. Ordenação. Sequenciação. Perguntas de leitura. Poema.

\begin{abstract}
The present study aims at discussing a proposal of ordering and sequencing of questions for the reading of the speech genre "poem" to be applied to Middle School students. Reading as interaction is the view underlying this study which is seen to contribute to student-readers' education and development. To this end, this study focuses on views on reading with emphasis on Applied Linguistics and the practice of ordering and sequencing of reading advocated by Solé (1998) and
\end{abstract}


broadened by Menegassi (2008; 2010; 2016), Fuza and Menegassi (2018; 2017) and Fuza (2017), which highlight the need of such a proposal as constituent of the process of reader development in school. Results reveal that ordering and sequencing of questions for the reading of the speech genre "poem" allow the student-reader to: (a) extract and assign meaning to what they read; (b) place themselves in a given position as regards the text theme; (c) produce a text as rebuttal/counterword.

Keywords: Reading. Ordering. Sequencing. Reading questions. Poem.

\section{Introdução}

O baixo rendimento em leitura no país é crescente, considerando-se a situação de ensino aprendizagem dessa habilidade e, consequentemente, a formação do leitor nas séries iniciais. Os resultados de avaliações feitas pelo Ministério da Educação, a exemplo da Prova Brasil, revelam que os alunos têm pouca capacidade leitora e que a formação de leitores críticos, em especial na rede pública, tem passado ainda longe das escolas (MENEGASSI, 2008).

Colomer e Camps (2002, p. 176), subsidiadas pelos trabalhos de Solé (1998), propõem que a escola atual transponha os muros da avaliação tradicional, que não avalia a formação do leitor em desenvolvimento, pela "avaliação formativa de leitura, definida no seio da concepção sociointeracionista de linguagem, que permite uma formação mais adequada do leitor nas séries iniciais, em função das situações de leitura da sociedade". Para Menegassi (2010a), a avaliação de leitura é um instrumento na situação de ensino de língua, sendo os princípios da avaliação, em qualquer disciplina, os mesmos, isto é, conhecer o que o aluno aprendeu. Com as novas concepções de ensino e, consequentemente, de leitura, a avaliação de leitura deve ser concebida sob um viés diferenciado da visão tradicional, que foca na prova de leitura oral, prova de questionário fechado de perguntas de compreensão, etc., que se mostram ineficazes na formação do leitor.

O trabalho com as perguntas de leitura, um dos instrumentos mais usados para avaliação de leitura em sala de aula, tem sua relevância, principalmente nas séries do Ensino Fundamental II, pois por meio delas forma-se e desenvolve-se o aluno-leitor. Para Solé (1998, p. 116), a leitura deve ser ensinada, "os alunos têm que assistir um processo/modelo de 
leitura que lhes permita ver as estratégias em ação em uma situação significativa e funcional". Com isso, é relevante que o professor proponha um modelo, um processo que oriente o aluno em sua leitura, ensinando-o a realizar atividades críticas.

Esta pesquisa tem como objetivo elaborar uma proposta de ordenação e sequenciação de perguntas de leitura à luz da Linguística Aplicada, destinada a alunos do $7^{\mathbf{0}}$ ano do Ensino Fundamental, para o gênero poema, contribuindo para os estudos sobre o ensino e a aprendizagem de língua materna, especificamente sobre as abordagens de formação e desenvolvimento do leitor em situação de ensino na escola. Procura-se analisar como ocorrem a ordenação e a sequenciação de perguntas de leitura voltadas ao gênero escolhido e caracterizar o processo a fim de compreender os conceitos envolvidos nessa perspectiva de trabalho, que se apresenta como uma possibilidade entre tantas outras já expostas pela literatura da área.

Optou-se pelo poema após o levantamento dos gêneros mais estudados pelos alunos, presentes na coleção de livros didáticos Português Linguagens, de William Roberto Cereja e Thereza Cochar Magalhães, do $6^{-}$ano ao $9^{-}$ano, empregada nas cidades de Porto Nacional e de Palmas, no estado do Tocantins, e também em várias escolas do país. Após esse estudo, um poema do livro do $7^{\underline{0}}$ ano foi selecionado em virtude de ser um gênero muito comum no material, e elaborou-se, com base na perspectiva interacionista de leitura, uma proposta de ordenação e sequenciação de perguntas de leitura.

\section{Concepções de leitura}

O processamento da leitura perpassa etapas, como as propostas por Menegassi (2016): primeiro, focando no texto, depois, no leitor, e, por fim, na interação autor, texto e leitor. Conforme Fuza (2010, p. 25), no processo de leitura "as perspectivas não ocorrem de forma isolada, não são meramente etapas sucedendo às outras, já que as práticas de leituras exigem o contínuo diálogo entre autor-texto-leitor", ou seja, uma perspectiva não isola a outra, mas possibilita a concretização do processo de leitura como interação. Assim, há diferentes perspectivas de leitura relacionadas aos processos de leitura: perspectiva do autor, do texto, do leitor e a interacionista, explicitadas na sequência. 
Segundo Menegassi (2010b), na concepção de leitura sob a perspectiva do autor, o leitor exerce um papel passivo diante do texto - é apenas um receptor das informações que o autor repassa em seu texto, ou seja, somente encontra o que o autor quis dizer. A leitura é entendida, então, como atividade de captação das ideias do autor, sem considerar as experiências e os conhecimentos do leitor, ou seja, a interação autor-textoleitor não se estabelece. Segundo Menegassi (2010b, p. 169), são exemplos de perguntas de leitura dessa concepção: " $\mathrm{O}$ que o autor quis dizer com...?"; " Segundo o autor,..."; " Para o autor do texto,...".

A concepção de leitura sob a perspectiva do texto centraliza-se no sistema linguístico como forma de extração, de decodificação, do falar bem, do que é certo ou errado, valoriza as formas gramaticais, sem ocorrer variação alguma, ou seja, centra-se exclusivamente no texto. Alguns exemplos de perguntas de leitura dessa concepção, conforme Menegassi (2010b, p. 170), são encontrados nos materiais didáticos e nas avaliações aplicadas em sala de aula: "Retire do texto a frase que expressa a ideia de...."; "Em qual parte do texto pode-se encontrar uma referência a...", ou seja, levam o aluno somente a identificar a resposta no texto.

$\mathrm{Na}$ concepção de leitura sob a perspectiva do leitor, este apresenta papel principal, pois atribui significados ao texto com base em seus conhecimentos prévios. Segundo Menegassi (2016) e Leffa (1996), essa concepção propicia ao leitor a criação de diferentes percepções do texto, entendendo que diferentes leitores trazem para a leitura conhecimentos prévios distintos, sustentando que o significado é construído com base nas ideias armazenadas do leitor. Menegassi e Angelo (2010, p. 19-20) apontam como exemplos de perguntas de leitura dessa concepção: "Em sua opinião,..."; "Comente sobre..."; "O final do texto é feliz ou triste? Justifique sua resposta."; "Explique, em poucas palavras, o que é...". Essas estratégias mostram que também a concepção de leitura com foco no leitor não leva o aluno ao desenvolvimento como leitor competente e crítico, apenas manifesta a continuação do processo de formação do leitor, sem ampliações nos seus horizontes de leitura. ${ }^{1}$

\footnotetext{
${ }^{1}$ Assim como Menegassi (2010c, p. 38), este trabalho considera a formação o momento da aquisição do código escrito. O desenvolvido é "parte do princípio de que a formação já foi evidenciada e o leitor já saiba dominar o sistema linguístico",
} 
As tentativas de trabalho com a leitura centrada na perspectiva da interação predominam da década de 1980 aos dias de hoje. Nela, autor, texto e leitor dialogam, estabelecendo o diálogo, a compreensão e a resposta ativas àquilo que lê. Os responsáveis por tratar dos aspectos dialógicos da linguagem são Bakhtin/Volochinov (1992[1929], p. 123), compreendendo a interação como a "realidade fundamental da língua". A alternância dos sujeitos no momento da leitura, isto é, a possibilidade que possuem de responder um ao outro, caracteriza um dos pressupostos baktiniamos. De acordo com Bakhtin (2003[1979]):

O ouvinte que recebe e compreende a significação de um discurso adota para com este discurso uma atitude responsiva ativa: ele concorda ou discorda, completa, adapta [...]. A compreensão de uma fala de um enunciado é sempre acompanhada de uma atitude responsiva ativa (BAKHTIN, 2003[1979], p. 271).

De acordo com os PCN (BRASIL, 1998), a leitura, como processo ativo, possibilita que o leitor realize um trabalho de construção de significado do texto, buscando extrair um significado já existente para, depois, produzir um sentido com base em seus objetivos e em seu conhecimento prévio. A leitura não é tida apenas como prática de extração, porque implica compreensão e conhecimentos prévios constituídos antes mesmo da leitura.

Busca-se, hoje, no contexto escolar, o trabalho com práticas que tendam à interação entre texto e leitor, estabelecendo-se a compreensão por meio de trocas de conhecimento e de informações. Nesse sentido, o texto é considerado "espaço de interlocução no qual intervêm elementos contextuais e intertextuais, uma vez que é resultado de absorções e transformações de outros textos" (DELL'ISOLA, 1996, p. 71). A interação estabelecida por meio da leitura passa a considerar o leitor coprodutor do texto, completando-o com sua bagagem histórico-cultural (DELL'ISOLA, 1996).

Fuza (2010) afirma que a melhor forma de desenvolver a leitura em sala de aula é promovendo o ecletismo entre as diversas concepções, uma

necessitando ir além no processo de leitura, chegando à compreensão e à interpretação. 
vez que cada uma enfoca especificidades fundamentais para o processo de construção do significado e para a produção de sentidos.

\subsection{Perguntas de leitura: instrumentos de avaliação}

O entendimento da avaliação de leitura como instrumento na situação de ensino de língua materna é primordial para que se compreenda que, por meio dela, se pode contribuir para a formação do leitor competente (BRASIL, 1998).

Para Colomer e Camps (2002), dois aspectos podem ser enumerados em torno da avaliação formativa:

1) é um instrumento nas mãos de todos os sujeitos envolvidos no ensino, isto é, todos têm o controle do processo, podendo visualizar seus erros e falhas para o aprimoramento e o crescimento; 2) a aprendizagem é entendida como uma construção do próprio aluno e implica uma mudança na utilização dos instrumentos de avaliação, que perdem seu habitual sentido sancionador (COLOMER; CAMPS, 2002, p. 172).

A avaliação formativa é, portanto, uma avaliação orientadora e global concebida como um meio pedagógico para ajudar o aluno em seu processo educativo. Menegassi (2008), ao tratar de avaliação formativa, que prevê a tríplice relação entre o aluno, o professor e a situação, pautando-se nos conceitos de Dell'Isolla (1996), menciona que as atividades com perguntas são extremamente importantes, porque possibilitam ao professor a orientação do aluno durante a leitura, "mediando, inclusive, sua formação. Dessa forma, as perguntas de leitura servem também para ensinar o leitor, para orientá-lo na sua aprendizagem, para auxiliá-lo na sua formação e desenvolvimento como leitor" (MENEGASSI, 2008, p. 6).

Além disso, Menegassi (2016) afirma que critérios de ordenação e sequenciação de perguntas estão relacionados ao conceito de leitura, "permitindo um trabalho de desenvolvimento cognitivo mais eficaz no aluno-leitor, a partir da conscientização do professor sobre as determinações teórico-metodológicas envolvidas nesse processo" (MENEGASSI, 2016, p. 48). 
A avaliação formativa de leitura exige a criação de novos instrumentos de avaliação (MENEGASSI, 1995, p. 75) que precisam atender às reais necessidades de desenvolvimento da leitura do aluno. Entender o processo de raciocínio exigido do aluno na hora da leitura é o primeiro passo; em seguida, é necessário compreender os resultados provenientes da avaliação. Um passo ocorre em função do outro, e estes levam a avanços repentinos e consideráveis no processo de leitura, assim como em qualquer processo de aprendizado. Nesse processo de avaliação formativa, o aluno não é mais avaliado bimestralmente, mas sim como um leitor em formação, em um processo contínuo, por meio do qual o professor acompanha o processo de ensino e de aprendizagem.

Fuza, Ohuschi, e Menegassi (2011) afirmam que, apesar da importância da construção de leitores que dialogam com o texto, com o outro e consigo mesmos, essa prática parece não ocorrer no contexto educacional, que permanece com as concepções isoladas de leitura como decodificação, privilegiando o texto ou o leitor, não havendo, assim, o diálogo entre esses elementos. Portanto, cabe às escolas ultrapassar esse modelo tradicional de trabalho com a leitura e conceber a avaliação de leitura de maneira formativa, como um processo, que deve ser ensinado por etapas, devendo o leitor ser acompanhado por meio de instrumentos de avaliação, auxiliando, assim, o aluno em seu processo educacional.

Dessa forma, ao trabalhar com as perguntas de leitura e sua sequenciação, possibilita-se ao aluno uma formação centrada no processo e não apenas na leitura final do texto, como produto. O leitor torna-se um indivíduo crítico capaz de relacionar algo que está no texto com seus conhecimentos de mundo, ou seja, ele não se prende ao texto, ocorrendo assim uma interação entre autor, texto e leitor. Por conseguinte, as perguntas de leituras são de suma importância para o desenvolvimento cognitivo e do ensino e aprendizagem do aluno (MENEGASSI, 2016).

Além de produzir perguntas de leituras com enfoque no autor, no texto, no leitor e na interação autor-texto-leitor, é preciso saber que estas últimas são classificadas, com base nos estudos de Solé (1998), de três formas possíveis: perguntas de respostas textuais, perguntas de respostas inferenciais e perguntas de respostas interpretativas (MENEGASSI, 2010b).

As perguntas de respostas textuais "são aquelas cujas respostas se encontram literal e diretamente no texto" (MENEGASSI, 2010b, p. 179). Não se restringem à cópia de partes do texto, cabendo ao leitor somente a 
realização do pareamento de informações do comando com a resposta no texto. Elas demandam a compreensão do enunciado por parte do aluno e o trabalho de interação com o texto para que a resposta seja elaborada.

Perguntas de respostas inferencias "podem ser deduzidas a partir do texto, isto é, elas estão ligadas ao texto, mas exigem que o leitor relacione os diversos elementos do texto lido, produzindo algum tipo de inferência" (MENEGASSI, 2010b, p. 180). Sendo assim, a resposta está no diálogo entre o texto e as inferências realizadas pelo leitor, que constrói uma resposta por meio da relação "pensar sobre o texto e buscar resposta fora dele" (MENEGASSI, 2010b, p. 180).

Perguntas de respostas interpretativas "são perguntas que tomam o texto como referencial, porém, as respostas não podem ser deduzidas exclusivamente dele, exigindo a intervenção do conhecimento prévio e da opinião do leitor" (MENEGASSI, 2010b, p. 181). Elas levam o aluno a produzir uma resposta pessoal, fazendo com que o aluno-leitor relacione o que lê e articule o tema do texto a sua vida: "Para isso, suas respostas não estão ligadas ao texto, mas, sim, às experiências de sua vida pessoal, criando uma interpretação textual própria" (MENEGASSI, 2010b, p.181).

Diante do exposto, segundo Menegassi (2010b; 2016), no trabalho com a leitura é preciso considerar o modo como as perguntas são sequenciadas: perguntas textuais, para que o aluno aprenda a trabalhar com o texto; logo após, apresentar as perguntas de respostas inferenciais, com a finalidade de o aluno estabelecer relações entre o texto e as informações que possui em seu conhecimento prévio; por último, propiciar perguntas de respostas interpretativas com o intuito de o aluno chegar à possibilidade de produzir sentidos próprios ao tema discutido. Portanto, conforme aponta Menegassi (2010b, 2016), com corroboração também de Rodrigues (2013), as perguntas precisam atender a uma ordem crescente de dificuldade, de modo que o leitor seja conduzido a uma progressiva reflexão sobre o texto com o qual está interagindo. Ressalta-se que essa proposta de trabalho deve ser parte do processo de desenvolvimento do leitor na escola, não podendo ser tomada como estratégia permanente de trabalho com o texto.

\section{Metodologia}

Esta pesquisa tem o objetivo de elaborar uma proposta de ordenação e sequenciação de perguntas de leitura do gênero poema 
Rayllane Cruz, Ângela Fuza e Renilson Menegassi

destinada a alunos do $7^{\underline{0}}$ ano do Ensino Fundamental. O resultado do levantamento dos gêneros propostos no livro didático citado é observado no Quadro 1.

\section{Quadro 1. Levantamento dos gêneros na coleção didática}

\begin{tabular}{|c|c|c|c|c|}
\hline Série & Unidade & Tema & Capítulo & Gênero \\
\hline \multirow{12}{*}{$\begin{array}{c}6^{0} \\
\text { ANO }\end{array}$} & \multirow{3}{*}{1} & \multirow{3}{*}{$\begin{array}{l}\text { No mundo } \\
\text { da fantasia }\end{array}$} & 1 & Poema; conto. \\
\hline & & & 2 & Pintura; conto; letra de música. \\
\hline & & & 3 & Poema; conto; receita; cartum. \\
\hline & \multirow{3}{*}{2} & \multirow{3}{*}{ Crianças } & 1 & $\begin{array}{l}\text { Poema; história em quadrinhos; } \\
\text { letra de música. }\end{array}$ \\
\hline & & & 2 & História em quadrinhos; fábula. \\
\hline & & & 3 & $\begin{array}{l}\text { Cartum; história em quadrinhos; } \\
\text { poema. }\end{array}$ \\
\hline & \multirow{3}{*}{3} & \multirow{3}{*}{$\begin{array}{l}\text { Descobrindo } \\
\text { quem sou eu }\end{array}$} & 1 & Poema. \\
\hline & & & 2 & Carta pessoal; poema. \\
\hline & & & 3 & Diário; poema. \\
\hline & \multirow{3}{*}{4} & \multirow{3}{*}{$\begin{array}{l}\text { Verde, } \\
\text { adoro ver- } \\
\text { te }\end{array}$} & 1 & Poema; pintura. \\
\hline & & & 2 & Crônica. \\
\hline & & & 3 & Reportagem. \\
\hline \multirow{12}{*}{$\begin{array}{c}7^{0} \\
\text { ANO }\end{array}$} & \multirow{3}{*}{1} & \multirow{3}{*}{ Heróis } & 1 & Poema; pintura. \\
\hline & & & 2 & Conto; pintura; poema. \\
\hline & & & 3 & Poema; história em quadrinhos. \\
\hline & \multirow{3}{*}{2} & \multirow{3}{*}{$\begin{array}{l}\text { Viagem } \\
\text { pela } \\
\text { palavra }\end{array}$} & 1 & Poema. \\
\hline & & & 2 & Pintura; poema. \\
\hline & & & 3 & Poema; letra de música. \\
\hline & \multirow{3}{*}{3} & \multirow{3}{*}{$\begin{array}{l}\text { Eu e os } \\
\text { outros }\end{array}$} & 1 & Conto. \\
\hline & & & 2 & Pintura; diário. \\
\hline & & & 3 & Notícia. \\
\hline & \multirow{3}{*}{4} & \multirow{3}{*}{$\begin{array}{l}\text { Medo, } \\
\text { terror e } \\
\text { aventura }\end{array}$} & 1 & Notícia; poema. \\
\hline & & & 2 & Entrevista. \\
\hline & & & 3 & Entrevista; conto. \\
\hline
\end{tabular}




\section{Quadro 1. Levantamento dos gêneros na coleção didática (cont.)}

\begin{tabular}{|c|c|c|c|c|}
\hline Série & Unidade & Tema & Capítulo & Gênero \\
\hline \multirow{12}{*}{$\begin{array}{c}8^{\mathbf{0}} \\
\text { ANO }\end{array}$} & \multirow{3}{*}{1} & \multirow{3}{*}{$\begin{array}{l}\text { O humor } \\
\text { nosso de } \\
\text { cada dia! }\end{array}$} & 1 & Crônica; teatro. \\
\hline & & & 2 & Poema; cartum. \\
\hline & & & 3 & $\begin{array}{l}\text { Comédia; reportagem; resenha } \\
\text { crítica; poema; letra de música. }\end{array}$ \\
\hline & \multirow{3}{*}{2} & \multirow{3}{*}{ Adolescer } & 1 & Crônica; poema \\
\hline & & & 2 & Crônica; pintura; notícia; anúncio. \\
\hline & & & 3 & $\begin{array}{l}\text { Pintura; crônica; artigo; poema; } \\
\text { anúncio. }\end{array}$ \\
\hline & \multirow{3}{*}{3} & \multirow{3}{*}{ Consumo } & 1 & Poema; cartum; anúncio; tira. \\
\hline & & & 2 & $\begin{array}{l}\text { Crônica; anúncio; carta; revista; } \\
\text { poema. }\end{array}$ \\
\hline & & & 3 & Poesia; anúncio; carta. \\
\hline & \multirow{3}{*}{4} & \multirow{3}{*}{$\begin{array}{c}\text { Ser } \\
\text { diferente }\end{array}$} & 1 & Poema; pintura; anúncio; cartum. \\
\hline & & & 2 & Entrevista; filme; poema. \\
\hline & & & 3 & Tira. \\
\hline \multirow{11}{*}{$\begin{array}{c}\mathbf{9}^{\mathbf{0}} \\
\text { ANO }\end{array}$} & \multirow{3}{*}{1} & \multirow{3}{*}{ Valores } & 1 & Poema; reportagem; cartum. \\
\hline & & & 2 & Pintura; reportagem; poema. \\
\hline & & & 3 & Crônica; anúncio; poema. \\
\hline & \multirow{2}{*}{2} & \multirow{2}{*}{ Amor } & 1 & Poema; conto; anúncio. \\
\hline & & & 2 & Pintura; conto; poema; anúncio. \\
\hline & \multirow{3}{*}{3} & \multirow{3}{*}{ Juventude } & 1 & $\begin{array}{l}\text { Poema; conto; anúncio; poema; } \\
\text { debate regrado; anúncio. }\end{array}$ \\
\hline & & & 2 & $\begin{array}{l}\text { Pintura; debate regrado; anúncio; } \\
\text { poema. }\end{array}$ \\
\hline & & & 3 & Conto; poema; tira. \\
\hline & \multirow{3}{*}{4} & \multirow{3}{*}{$\begin{array}{l}\text { Nosso } \\
\text { tempo }\end{array}$} & 1 & Poema; cartum. \\
\hline & & & 2 & Cartum; anúncio. \\
\hline & & & 3 & Carta; poema. \\
\hline
\end{tabular}

FONTE: elaboração dos autores

Diante do levantamento, há nos livros o seguinte número de textos: 32 poemas, 11 anúncios, dez contos, oito cartuns, oito pinturas, sete crônicas, quatro reportagens, quatro letras de música, quatro histórias em quadrinhos, quatro reportagens, três entrevistas, três notícias, três tiras, três cartas, dois debates integrados, uma receita, um filme, um artigo, um diário, uma fábula, uma resenha crítica. Verifica-se que o gênero poema é o mais 
recorrente, por esse motivo este estudo optou por trabalhar com a proposta de ordenação e de sequenciação de perguntas para ele.

O trabalho selecionou o poema de Elias José "Autoapresentação", encontrado no livro didático do $7^{\underline{0}}$ ano.

\section{0 trabalho com a leitura do gênero poema}

A fim de expor de que modo os conceitos teóricos podem ser empregados em sala de aula, apresenta-se o poema "Autoapresentação".

\section{Excerto 1. Poema Autoapresentação.}

Sou o poeta João,

Cheio de sonhos e pesadelos

E medos e coragem.

Tenho os olhos abertos, espertos

Para olhar o céu, o mar, a montanha

E todas as cores que a vida tem.

Tantos me tocam as cores $d a$

natureza

Como os olhos das garotas.

Tenho os ouvidos atentos

para a música, os ruídos todos

e a sonoridade dos sorrisos

e dos nomes de mulher.

Com os íntimos ou escrevendo

Sou falante, elétrico como um grilo.

Quando enfrento o desconhecido

Sou caracol encolhido em minha casca-casa.

Sou alegre e sou triste, Sou poeta em projeto.

Acho que o poeta é um cara-de-pau

Que se joga todo sem redes,

Sem máscaras e sem olhos escuros.

É um ser que bota fogo no gelo

E espera um incêndio amazônico.

Para isso vivo e me preparo

Como só tenho quinze anos,

Estou ainda atiçando chispas.

Se uma chamazinha explodir,

Se um verde minúsculo brotar

Do azul do meu poema,

Se o diálogo quebrar a indiferença,

Valeu.

(Elias José)

Fonte: Cereja e Magalhães (2012, p. 195) 
Foram destacadas as diferentes concepções de leitura - com foco no autor, no texto, no leitor e na interação -, assim como o modo como cada uma delas concebe as perguntas de leitura. Dessa forma, é apresentada uma sequência de perguntas de leitura que, por uma questão didática, foi separada seguindo as concepções para possibilitar a melhor compreensão sobre cada uma delas. Ressalta-se que no material didático o poema vinha acompanhado de oito questões de leitura, sendo quatro com foco no texto; três com foco no ensino gramatical; uma com foco no leitor, sem a preocupação com sua sequenciação. Diante disso, optou-se por elaborar novas perguntas que serão discutidas:

\section{Excerto 2. Perguntas de leitura.}

PERGUNTAS COM FOCO NO AUTOR

I. Quem é o eu lírico do poema?

II. O que o eu lírico deseja se tornar?

\section{PERGUNTAS COM FOCO NO TEXTO}

III. Do que o poeta João é cheio?

IV. O que João tem ouvidos atentos para ouvir?

V. Qual é a atitude de João com os intimos?

VI. Como João define o poeta na quarta estrofe?

\section{PERGUNTAS COM FOCO NO LEITOR}

VII. Qual sua opinião sobre o personagem do poema?

VIII. Você já realizou uma autoapresentação?

\section{PERGUNTAS COM FOCO NA INTERAÇÃO AUTOR-TEXTO-LEITOR}

a) Perguntas de resposta textual

IX. Por que o título do poema é "Autoapresentação”?

$X$. Por que o eu lírico é tocado tanto pelas cores da natureza quanto pelos olhos das garotas na primeira estrofe?

XI. Por que o eu lírico se compara a um grilo na terceira estrofe?

XII. Por que o eu lírico compara o poeta a um cara-de-pau?

XIII. O eu lírico acredita já estar preparado como poeta?

b) Perguntas de resposta inferencial

$X I V$. Por que o eu lírico estabelece relação entre os elementos da natureza e os olhos das garotas na primeira estrofe? 
$X V$. Por que o eu lírico fica atento à sonoridade dos sorrisos e dos nomes das mulheres na segunda estrofe?

$X V I$. Por que com os íntimos o eu lírico é falante e com o desconhecido se torna um caracol em sua casca-casa?

XVII. Por que o eu lírico diz que é um "poeta em projeto"?

XVIII. Na última estrofe, o eu lírico do poema diz ser jovem e que seu poema terá valido a pena se realizar o quê na vida das pessoas?

c) Perguntas de resposta interpretativa

XIX. Você também é cheio(a) de sonhos e de medos assim como o eu lírico do poema? Quais são eles?

XX. Assim como o João tem os ouvidos atentos, os seus são atentos a $q u \hat{e} ?$

XXI. O que você acha que o poeta já enfrentou de desconhecido que o fazia se comportar como um "caracol encolhido em minha cascacasa"?

XXII. O autor sente-se como um poeta em seu texto. Você já se sentiu um poeta ou atuando em outra atividade/profissão?

XXIII. Quais características colocaria sobre você se fosse escrever uma autoapresentação?

Fonte: Os autores.

Diante do exposto, parte-se para a discussão sobre as perguntas elaboradas.

\subsection{Perguntas com foco no autor}

I. Quem é o eu lírico do poema?

Resposta: O eu lírico do poema é João.

II. O que o eu lírico deseja se tornar?

Resposta: $O$ eu lírico deseja se tornar um poeta.

Observa-se que as perguntas I e II são de uma tipologia tradicional, envolvendo respostas copiadas do texto, relacionadas ao reconhecimento das intenções do autor e do eu lírico. O aluno é impedido de produzir sentidos próprios ao texto, porque a informação que lhe é solicitada, pela concepção de leitura com foco no autor, é a de repetição, reprodução, não sendo permitida a réplica, no sentido bakhtiniano de responsividade ativa (BAKHTIN, 2003[1979]. Isto é, no sentido de produção de uma leitura própria, em que as ideias e as 
palavras do leitor possam ser manifestadas por respostas a perguntas de leitura. Em relação a essas perguntas, o leitor é apenas um receptor das informações que o autor repassa em seu texto.

\subsection{Perguntas com foco no texto}

III. Do que o poeta João é cheio?

Resposta: $O$ poeta João é cheio de sonhos e pesadelos e medos e coragem.

IV. O que João tem ouvidos atentos para ouvir?

Resposta: O poeta João tem ouvidos atentos para a música, para os ruídos e para a sonoridade dos sorrisos e dos nomes de mulher.

V.Qual a atitude de João com os íntimos?

Resposta: Com os íntimos, João é falante e elétrico.

VI.Como João define o poeta na quarta estrofe?

Resposta: João define o poeta como um cara-de-pau.

Nas perguntas de números III a VI, o foco está no texto, pois são respondidas perfeitamente sem qualquer dificuldade, basta o leitor seguir a sequência do poema para que as respostas sejam produzidas, copiando partes de informações textuais. Alguns exemplos: "III. Do que o poeta João é cheio? e V. O que João tem ouvidos atentos para ouvir?" são perguntas cujas respostas se acham centradas exclusivamente no texto, exigindo que o leitor atente para os dados presentes na superfície textual, reconheça os símbolos escritos e ligueos a um significado. Marcuschi (2008) denomina essas questões como "perguntas cópias", pois são atividades mecânicas de transcrição de frases, que não exigem trabalho de reflexão do leitor.

Nota-se que nas concepções de leitura com foco no autor e no texto a leitura é caracterizada como passiva e de simples reconhecimento de palavras e ideias, e o papel do leitor é extrair conteúdo do texto (KLEIMAN, 1996; MENEGASSI; ANGELO, 2010).

Segundo Menegassi e Angelo (2010, p. 19), a concepção de leitura com foco no texto tem uma perspectiva ideológica definida. Quanto mais o aluno responde às perguntas de identificação textual, 
menos desenvolve a capacidade de produção de sentidos, consequentemente não amadurece sua posição crítica diante dos textos que circulam em seu grupo social, na sociedade como um todo e na própria escola em que se encontra. Ela é uma concepção necessária à formação do leitor, contudo sua manutenção como estratégia de ensino de leitura não permite o desenvolvimento desse leitor, por isso é preciso considerar a fase da extração apenas uma parte do processo.

\subsection{Perguntas com foco no leitor}

\section{Qual sua opinião sobre o personagem do poema?}

\section{Você já realizou uma autoapresentação?}

Nas perguntas de números VII e VIII, o foco do processo de leitura está no leitor. Para as duas perguntas, qualquer resposta serve, basta apenas ao leitor apresentar uma simples possibilidade de sentido. As respostas possíveis para essas perguntas são muito abertas, configurando-se no que Marcuschi (2008, p. 271) classifica como perguntas "subjetivas" e "vale-tudo". As primeiras, em geral, "têm a ver com o texto de maneira apenas superficial, sendo que a $\mathrm{R}$ [resposta] fica por conta do aluno e não há como testá-las em sua validade". Já as vale-tudo "indagam sobre questões que admitem qualquer resposta, não havendo possibilidade de se equivocar".

Segundo Menegassi (2010b), embora exijam a participação do leitor durante a leitura, essas perguntas descartam os aspectos sociais em volta do leitor, confiando exageradamente nas "adivinhações" que produzem, considerando possível qualquer significado apresentado por ele, dando origem a um vale-tudo na leitura.

Por estar centrada no leitor, essa concepção aceita diferentes compreensões de um texto, porque há diferentes leitores, com diferentes conhecimentos prévios. Isso mostra que o sentido do texto é construído de modo descendente, isto é, vai da mente do leitor para o texto (KLEIMAN, 1996; MENEGASSI; ANGELO, 2010). As perguntas com foco no leitor devem constituir parte do processo de leitura, em diálogo com as de extração, possibilitando que o aluno possa iniciar uma compreensão do texto e, posteriormente, a interpretação. Destaca-se que essas perguntas também podem ser 
apresentadas, por exemplo, na fase da pré-leitura do texto, ou seja, antes da leitura, a fim de permitir ao aluno a retomada de seus conhecimentos prévios e a ativação de outros.

\subsection{Perguntas com foco na interação autor-texto-leitor}

\subsubsection{Perguntas de resposta textual}

O primeiro nível de perguntas apresentadas por Menegassi (2016) são as perguntas de resposta textual, denominadas por Solé (1998) como literais, cujas respostas se encontram diretamente no texto. Observa-se que não são perguntas com respostas de cópia, em que basta ao leitor copiar um trecho do texto e transferi-lo como sendo de resposta, assim como acontece nas perguntas de foco no texto/extração. Os exemplos de perguntas textuais são:

IX. Por que o título do poema é "Autoapresentação"?

Resposta: O título do poema é Autoapresentação porque o poeta João descreve a si mesmo no decorrer do texto, faz uma breve apresentação, de como ele é e o que ele tem.

$X$. Por que o eu lírico é tocado tanto pelas cores da natureza quanto pelos olhos das garotas na primeira estrofe?

Resposta: $O$ eu lírico é tocado tanto pelas cores da natureza quanto pelos olhos das garotas porque ele aprecia muito a natureza, as cores e a vida.

XI. Por que o eu lírico se compara a um grilo na terceira estrofe?

Resposta: $O$ eu lírico se compara a um grilo, pois, quando está com os íntimos ou escrevendo, ele é falante e elétrico; não para, assim como o grilo é.

XII. Por que o eu lírico compara o poeta a um cara-de-pau?

Resposta: O eu lírico compara o poeta a um cara-de-pau, pois, o poeta na hora da escrita escreve o que bem quer, não tem vergonha de se expor, se expressa de toda forma e nem se preocupa em esconder alguma coisa.

XIII. O eu lírico acredita já estar preparado como poeta? 
Resposta: O eu lírico não acredita já estar preparado como poeta porque ele afirma no poema que está em projeto, ou seja, ainda está em formação para tornar-se um grande poeta.

$\mathrm{Na}$ questão "IX. Por que o título do poema é “Autoapresentação?”, nota-se que é uma pergunta que indaga o porquê do título do poema, exigindo do aluno que faça uma busca no texto para identificar os elementos que podem ser usados como resposta. Contudo, não permite que ele encontre a resposta pronta. Essa pergunta exige do aluno a compreensão do seu enunciado e um trabalho efetivo de interação com o texto para que a resposta seja produzida.

Outro exemplo, "XI. Por que o eu lírico é tocado tanto pelas cores da natureza quanto pelos olhos das garotas na primeira estrofe?" demonstra que a pergunta tem ligação direta com o texto, porém as respostas não são copiadas, pois o aluno-leitor deve realizar um trabalho de interação com o texto para produzi-las. Nesse caso, tendo em vista o diálogo com o texto, o aluno inicia um processo de compreensão textual daquilo que lê, indo além da mera decodificação de informações.

\subsubsection{Perguntas de resposta inferencial}

O segundo nível de perguntas apresentadas por Menegassi (2010b) são aquelas cujas respostas podem ser deduzidas com base no texto, isto é, estão ligadas ao texto, mas exigem que o leitor relacione os diversos elementos do texto lido, produza algum tipo de inferência e relacione o texto com seu conhecimento próprio. As perguntas são:

XIV. Por que o eu lírico estabelece relação entre os elementos da natureza e os olhos das garotas, na primeira estrofe?

Resposta: Acho que o eu lírico estabelece a relação entre os elementos da natureza e os olhos das garotas, por que os olhos são tão belos quanto à natureza em si, e também por que ele aprecia muito a natureza, as cores e a vida.

XV. Por que o eu lírico fica atento à sonoridade dos sorrisos e dos nomes das mulheres, na segunda estrofe?

Resposta: Acho que o eu lírico fica atento à sonoridade das mulheres, porque ele está na adolescência e é a fase em que começa 
Ordenação e sequenciação de perguntas de leitura...

a olhar diferente para as meninas, então, é algo que chama a atenção dele.

XVI. Por que, com os íntimos, o eu lírico é falante e com o desconhecido se torna um caracol em sua casca-casa?

Resposta: Acredito que com os íntimos o eu lírico é falante, por que sente se mais a vontade para conversas e quando o poeta enfrenta o desconhecido se torna um caracol em sua casca-casa, por que ele fica quieto, sozinho e tímido.

XVII. Por que o eu lírico diz que é um "poeta em projeto"?

Resposta: $O$ eu lírico diz que é um poeta em projeto, pois ainda é um adolescente, só tem quinze anos e agora que começou a escrever alguns versos.

XVIII. Na última estrofe, o eu lírico do poema diz ser jovem e que o seu poema terá valido a pena se realizar o quê na vida das pessoas? Resposta: O poema terá valido a pena se o diálogo quebrar a indiferença, ou seja, se ocorrer um diálogo, uma interação entre o poema e o leitor.

As questões de números XIV a XVIII são perguntas de resposta inferencial ou "perguntas para pensar e buscar" (SOLÉ, 1998), pois as respostas podem ser deduzidas com base no texto, isto é, elas estão ligadas ao texto, mas exigem que o leitor relacione os diversos elementos do texto lido, produzindo algum tipo de inferência. Por exemplo, "XVI. Por que, com os íntimos, o eu lírico é falante e com o desconhecido se torna um caracol em sua casca-casa?”. A resposta para esta pergunta não está literalmente no texto "Autoapresentação", mas remete a uma parte dele: "Com os íntimos ou escrevendo/Sou falante, elétrico como um grilo./Quando enfrento o desconhecido/Sou caracol encolhido em minha casca-casa", cabendo ao aluno inferir, utilizando seus conhecimentos prévios, que o desconhecido geralmente pode causar medo, fazendo com que a pessoa fique acuada e isolada.

Assim, percebe-se que o aluno relaciona o texto ("com os íntimos, o narrador é falante e com o desconhecido se torna um caracol em sua casca-casa") e sua vida ("Por que você acredita") para responder. $\mathrm{O}$ foco da resposta não permanece só no conhecimento do leitor, assim como pode acontecer nas perguntas de foco exclusivo no 
leitor, mas sim no diálogo entre ele e aquilo que lê, iniciando sua compreensão extratextual.

\subsubsection{Perguntas de resposta interpretativa}

As perguntas de resposta interpretativa remetem o leitor a elaborar uma resposta pessoal, contudo não vale qualquer resposta. Destacam-se os exemplos:

XIX. Você também é cheio(a) de sonhos e de medos assim como o eu lírico do poema? Quais são eles?

Resposta: Eu também sou cheio(a) sonhos e medos, como, por exemplo, meu sonho é realizar-me profissionalmente e o meu maior medo é de perder as pessoas que amo.

XX. Assim como o João tem os ouvidos atentos, os seus são atentos a quê?

Resposta: Assim como o João tem os ouvidos atentos, os meus são atentos para qualquer barulho, como a música, conversas, entre outros.

XXI. O que você acha que o poeta já enfrentou de desconhecido que o fazia se comportar como um "caracol encolhido em minha cascacasa"?

Resposta: Acho que quando poeta enfrenta o desconhecido ele se comporta com timidez, quando ele encontra pessoas diferentes, quando tem medo de alguma coisa, ele fica quieto e utiliza uma metáfora no poema para mostrar isso.

XXII. O autor sente-se como um poeta em seu texto. Você já se sentiu um poeta ou atuando em outra atividade/profissão?

Resposta: Eu já me senti um poeta em algum momento da minha vida, pois a poesia é algo mágico, que nos faz usar a imaginação e "viajar" para qualquer lugar, através da escrita e da imaginação.

XXIII. Quais características colocaria sobre você se fosse escrever uma autoapresentação?

Resposta: Se eu fosse escrever uma autoapresentação minha, escreveria as minhas principais características como, sou baixinha, tenho cabelos escuros e ondulados, sou alegre, tenho vários sonhos e procuro alcançá-los. 
As questões de XIX a XXIII são interpretativas, pois tomam o texto como referencial. Porém, as respostas não podem ser deduzidas exclusivamente dele, exigindo a intervenção do conhecimento prévio e da opinião do leitor, apresentando um cunho mais pessoal. A produção de sentidos está necessariamente atrelada às perguntas anteriores, que levam o aluno-leitor a raciocinar sobre o que está lendo e a articular o tema do texto à sua vida pessoal. Para isso, suas respostas não estão ligadas ao texto, mas, sim, às experiências de sua vida pessoal, criando uma interpretação textual própria.

Em todas essas perguntas (XIX a XXIII), as respostas não são encontradas no texto. Elas são produzidas com base na elaboração pessoal do leitor sobre os conhecimentos e as experiências de sua vida, contudo são relacionadas ao tema discutido no poema "Autoapresentação". Dessa forma, não é qualquer sentido que vale nessa interação, pelo contrário, somente aqueles pertinentes à enunciação marcada.

As perguntas interpretativas "são sempre apresentadas numa ordem final, depois que as demais perguntas levaram o aluno-leitor a trabalhar com o texto" (MENEGASSI, 2011, p. 29). Assim, ao chegar a essa resposta o leitor já está preparado para atribuir sentido ao tema, caso contrário ele poderá atribuir uma resposta de vale-tudo. Por conseguinte, "essa estratégia demonstra como a construção, a ordenação e a sequenciação de perguntas são uma noção essencial à prática de avaliação de leitura" (MENEGASSI, 2011, p. 29).

De acordo com a proposta, à luz dos estudos de Menegassi (2010b), constata-se que, ao responder às questões, o aluno passa por um processo de constituição da leitura. Inicia com perguntas voltadas ao autor, extraindo informações do texto, verificando de que forma o personagem é apresentado: cheio de sonhos, pesadelos, com ouvidos atentos, falante com os íntimos e acreditando que o poeta é um carade-pau. Depois, o leitor é chamado a atribuir sentidos ao que lê, de modo aberto, subjetivo, questionando-se a opinião dele sobre a personagem, se ele já realizou uma autoapresentação.

Para Angelo e Menegassi (2014), essas três classificações (textual, inferencial e interpretativa) necessitam ser trabalhadas em sala de aula, visto que englobam todas as etapas do processamento da leitura. Além disso, segundo os autores, é preciso também levar em 
consideração o modo como as perguntas são ordenadas: primeiramente, oferecer perguntas de resposta textual para que o aluno aprenda a trabalhar com o texto; após, apresentar as perguntas de resposta inferencial com a finalidade de o aluno estabeler relações entre o texto e as informações que possui em seu conhecimento prévio; por último, propiciar perguntas de resposta interpretativa com o intuito de o aluno chegar à possibilidade de produzir sentidos próprios ao tema discutido. Portanto, conforme apontam Angelo e Menegassi (2014) e Menegassi (2016), assim como Rodrigues (2013), as perguntas precisam atender a uma ordem crescente de dificuldades, conduzindo o leitor a uma progressiva reflexão sobre o texto com o qual está interagindo.

De acordo com Menegassi (2016), após a leitura do texto, por meio das questões textuais, inferenciais e interpretativas, o aluno é orientado a produzir outra resposta, que agrupa as informações das respostas anteriores em uma só pergunta: "Do que trata o texto? (a partir das respostas das perguntas anteriores, construa um texto expressando sua interpretação)". Isso possibilitará ao aluno reunir as ideias anteriores, destacando-se a construção de parágrafo que, para Garcia (1992), é constituído de: afirmação inicial, explicação sobre essa afirmação e exemplificação dessa explicação. Angelo (2015) expõe: "Afirmação inicial retirada do texto - que coincide com a resposta textual; explicação sobre essa afirmação - que surge da resposta inferencial; e exemplificação dessa explicação, a partir de elementos da vida pessoal do leitor - a partir da resposta interpretativa" (ANGELO, 2015, p. 58). Menegassi (2010a) afirma que esses procedimentos não devem ser empregados por muito tempo, pois é possível que se produza "um estruturalismo definido para a produção textual, que não atende ao trabalho criativo que deve ser usado cotidianamente na sala de aula na produção de gêneros textuais" (2010a, p. 187). Então, a metodologia é adequada para a fase entre a formação e o desenvolvimento do leitor, como o caso dos alunos do $7^{\text {o }}$ ano do Ensino Fundamental.

São apresentadas as respostas atribuídas às perguntas de forma que constituam um texto por meio da justaposição das ideias, dando origem a uma produção textual escrita do gênero resposta argumentativa, um texto eminentemente escolar, porém com qualidades de desenvolvimento do leitor e do produtor de textos. 


\section{Figura 1. Produção textual 1.}

9. $\mathrm{O}$ título do poema é Autoapresentação porque o poeta João descreve a si mesmo no decorrer do texto, faz uma breve apresentação, de como ele é e o que ele tem. $\mathbf{1 0}$. O eu lírico é tocado tanto pelas cores da natureza quanto pelos olhos das garotas porque ele aprecia muito a natureza, as cores e a vida. 11. O eu lírico se compara a um grilo, pois, quando está com os intimos ou escrevendo, ele é falante e elétrico; não para, assim como o grilo é.12. O eu lírico compara o poeta a um cara-de-pau, pois, o poeta na hora da escrita escreve o que bem quer, não tem vergonha de se expor, se expressa de toda forma e nem se preocupa em esconder alguma coisa. 13. $\mathrm{O}$ eu lírico não acredita já estar preparado como poeta porque ele afirma no poema que está em projeto, ou seja, ainda está em formação para tornar-se um grande poeta. 14. Acho que o eu lírico estabelece a relação entre os elementos da natureza e os olhos das garotas, por que os olhos são tão belos quanto à natureza em si, e também por que ele aprecia muito a natureza, as cores e a vida. $\mathbf{1 5}$. Âcho que o eu lírico fica atento à sonoridade das mulheres, porque ele está na adolescência e é a fase em que começa a olhar diferente para as meninas, então, é algo que chama a atenção dele. 16. Acredito que com os intimos o eu lirico é falante, por que sente se mais a vontade para conversas e quando o poeta enfrenta o desconhecido se torna um caracol em sua casca-casa, por que ele fica quieto, sozinho e tímido. 17. $\mathrm{O}$ eu lírico diz que é um poeta em projeto, pois ainda é um adolescente, só tem quinze anos e agora que começou a escrever alguns versos.18. O poema terá valido a pena se o diálogo quebrar a indiferença, ou seja, se ocorrer um diálogo, uma interação entre o poema e o leitor.19. Eu também sou cheio(a) sonhos e medos, como, por exemplo, meu sonho é realizar-me profissionalmente e o meu maior medo é de perder as pessoas que amo. 20 . Assim como o João tem os ouvidos atentos, os meus são atentos para qualquer barulho, como a música, conversas, entre outros. 21. Acho que quando poeta enfrenta o desconhecido ele se comporta com timidez, quando ele encontra pessoas diferentes, quando tem medo de alguma coisa, ele fica quieto e utiliza uma metáfora no poema para mostrar isso. 22. Eu já me senti um poeta em

Afirmação inicial

(respostas de 9 a 13)

\section{Explicação}

(respostas de 14 a 18) algum momento da minha vida, pois a poesia é algo mágico, que nos faz usar a imaginação e "viajar" para qualquer lugar, através da escrita e da imaginação. 23. Se eu fosse escrever uma autoapresentação minha, escreveria as minhas principais características como, sou baixinha, tenho cabelos escuros e ondulados, sou alegre, tenho vários sonhos e procuro alcançá-los.

\section{Fonte: Os autores.}

O aluno inicia usando a justaposição das respostas encadeadas, um processo de construção de parágrafo. Por isso a relevância do trabalho com a leitura de forma ordenada e sequenciada, possibilitando-lhe constituir seus próprios dizeres, uma réplica. Para Rodrigues (2016), “o processo de construção leitora permite ensinar o aluno a construção de parágrafos completos, constituídos inicialmente a partir da justaposição das perguntas, que propiciaram ao aluno desenvolver ou explanar determinada ideia central (GARCIA, 1969)" (RODRIGUES, 2016, p. 28).

$\mathrm{Na}$ justaposição, o aluno constrói e reconstrói a primeira versão do seu texto com a mediação do professor. Assim, realiza acréscimos e substituições - destacados em itálico no texto - e supressões de redundâncias - destacadas com tachado - em seu texto, conforme o Excerto 3.

\section{Excerto 3. Primeira versão do texto.}


[O texto trata do] $\Theta$ títmlo do poema é Autoapresentação porque $\theta$ poeta João [que] descreve a si mesmo no-decorrer do texte, faz [por meio de] uma breve apresentação, de como ele é e o que ele tem. [Segundo o] $\theta$ eu lírico [, ele] é tocado tanto pelas cores da natureza quanto pelos olhos das garotas porque ele-aprecia muito a natureza, as cores e a vida. O-u lírice [Ele]se compara a um grilo, pois, quando está com os íntimos ou escrevendo, ele é falante e elétrico; não para, assim como o grilo é. O eu lírice [Além disso,] compara o poeta a um cara-de-pau, pois, o poeta na hora da escrita escreve o que bem quer, não tem vergonha de se expor, se expressa de toda forma e nem se preocupa em esconder alguma coisa. $\mathrm{O}$ eu lírico não acredita já estar preparado como poeta porque ele afirma no poema que está em projeto, ou seja, ainda está em formação para tornar-se um grande poeta. Acho-que - eu lírico-[O eu lírico] estabelece a relação entre os elementos da natureza e os olhos das garotas, porque os olhos são tão belos quanto à natureza em si, e também porque ele aprecia muito a natureza, as cores e a vida. Acho que o eu lírice [Ele] fica atento à sonoridade das mulheres, porque ele está na adolescência e é a fase em que começa a olhar diferente para as meninas, então, é algo que chama a atenção dele. Acredito que [C]om os íntimos o eu lírico é falante, porque sente se mais a vontade para conversar e quando o poeta enfrenta o desconhecido se torna um caracol em sua casca-casa, por que ele fica quieto, sozinho e tímido. O eu lírico diz que é um poeta em projeto, pois ainda é um adolescente, só tem quinze anos e agora que começou a escrever alguns versos. O poema terá valido a pena se o diálogo quebrar a indiferença, ou seja, se ocorrer um diálogo, uma interação entre o poema e o leitor. Eu também sou cheio(a) sonhos e medos, como, por exemplo, meu sonho é realizar-me profissionalmente e o meu maior medo é de perder as pessoas que amo. Assim como o João tem os ouvidos atentos, os meus são atentos para qualquer barulho, como a música, conversas, entre outros. Acho que quando poeta enfrenta o desconhecido ele se comporta com timidez, quando ele encontra pessoas diferentes, quando tem medo de alguma coisa, ele fica quieto e utiliza uma metáfora no poema para mostrar isso. Eu já me senti um poeta em algum momento da minha vida, pois a poesia é algo mágico, que nos faz usar a imaginação e "viajar" para qualquer lugar, através da escrita e da imaginação. Se eu fosse escrever uma autoapresentação minha, escreveria as minhas principais características como, sou baixinha, tenho cabelos escuros e ondulados, sou alegre, tenho vários sonhos e procuro alcançá-los.

Fonte: Os autores.

O aluno reflete quando apaga, acrescenta e reconstrói seu texto, seguindo seu pensamento que foi organizado pela sequência de perguntas. Dessa forma: 
A estrutura da resposta completa, construída a partir da ordenação e sequenciação, culmina no texto da resposta-final, auxilia muito na reflexão do aluno diante da leitura, propicia-lhe análise de suas próprias acepções, julgamentos e conclusões, proporcionando principalmente um posicionamento independente e autônomo diante do texto lido, concretizando, portanto, o processo de interação [...] (MENEGASSI, 2016, p. 56).

Sendo assim, as duas versões são expostas em comparação no Quadro 1.

\section{Quadro 1. Comparação entre versões.}

\begin{tabular}{|c|c|}
\hline al & ão da resposta final \\
\hline $\begin{array}{l}\text { 9. O título do poema é } \\
\text { Autoapresentação porque o poeta } \\
\text { João descreve a si mesmo no } \\
\text { decorrer do texto, faz uma breve } \\
\text { apresentação, de como ele é e o que } \\
\text { ele tem. 10. O eu lírico é tocado } \\
\text { tanto pelas cores da natureza quanto } \\
\text { pelos olhos das garotas porque ele } \\
\text { aprecia muito a natureza, as cores e } \\
\text { a vida. 11. O eu lírico se compara a } \\
\text { um grilo, pois, quando está com os } \\
\text { íntimos ou escrevendo, ele é falante } \\
\text { e elétrico; não para, assim como o } \\
\text { grilo é. 12. O eu lírico compara o } \\
\text { poeta a um cara-de-pau, pois, o } \\
\text { poeta na hora da escrita escreve o } \\
\text { que bem quer, não tem vergonha de } \\
\text { se expor, se expressa de toda forma } \\
\text { e nem se preocupa em esconder } \\
\text { alguma coisa. 13. O eu lírico não } \\
\text { acredita já estar preparado como } \\
\text { poeta porque ele afirma no poema }\end{array}$ & $\begin{array}{l}\text { é Autoapresentação porque }{ }^{2} \\
\text { João [que] descreve a si mesm } \\
\text { decorrer do texte, faz-[por meic } \\
\text { uma breve apresentação, de com } \\
\text { é e o que ele tem. [Segundo } \\
\text { narrador [, ele] é tocado tanto } \\
\text { cores da natureza quanto pelos } \\
\text { das garotas porque ele-aprecia n } \\
\text { a natureza, as cores e a vida. } \Theta \\
\text { [Ele]se compara a um grilo, } \\
\text { quando está com os íntimos } \\
\text { escrevendo, ele é falante e elét } \\
\text { não para, assim como o grilo } \\
\text { narrador [Além disso,] compa } \\
\text { poeta a um cara-de-pau, pois, o } 1 \\
\text { na hora da escrita escreve o que } \\
\text { quer, não tem vergonha de se e } \\
\text { se expressa de toda forma e ne } \\
\text { preocupa em esconder alguma c } \\
\text { O narrador não acredita já } \\
\text { preparado como poeta porque }\end{array}$ \\
\hline
\end{tabular}


está em formação para tornar-se um grande poeta. 14. Acho que o eu lírico estabelece a relação entre os elementos da natureza e os olhos das garotas, por que os olhos são tão belos quanto à natureza em si, e também por que ele aprecia muito a natureza, as cores e a vida.15. Acho que $\mathrm{o}$ eu lírico fica atento à sonoridade das mulheres, porque ele está na adolescência e é a fase em que começa a olhar diferente para as meninas, então, é algo que chama a atenção dele.16. Acredito que com os íntimos o eu lírico é falante, por que sente se mais a vontade para conversas e quando o poeta enfrenta o desconhecido se torna um caracol em sua casca-casa, por que ele fica quieto, sozinho e tímido. 17. $\mathrm{O}$ eu lírico diz que é um poeta em projeto, pois ainda é um adolescente, só tem quinze anos e agora que começou a escrever alguns versos.18. O poema terá valido a pena se o diálogo quebrar a indiferença, ou seja, se ocorrer um diálogo, uma interação entre o poema e o leitor.19. Eu também sou cheio(a) sonhos e medos, como, por exemplo, meu sonho é realizar-me profissionalmente e o meu maior medo é de perder as pessoas que amo. 20. Assim como o João tem os ouvidos atentos, os meus são atentos para qualquer barulho, como a música, conversas, entre outros. 21. Acho que quando poeta enfrenta o desconhecido ele se comporta com timidez, quando ele encontra pessoas diferentes, quando tem medo de ou seja, ainda está em formação para tornar-se um grande poeta. Acho que o autor-[O narrador] estabelece a relação entre os elementos da natureza e os olhos das garotas, porque os olhos são tão belos quanto à natureza em si, e também porque ele aprecia muito a natureza, as cores e a vida. Acho que o alltor [Ele] fica atento à sonoridade das mulheres, porque ele-está na adolescência e é a fase em que começa a olhar diferente para as meninas, então, é algo que chama a atenção dele. Acredito que [C]om os íntimos o narrador é falante, porque sente se mais a vontade para conversar e quando o poeta enfrenta o desconhecido se torna um caracol em sua casca-casa, por que ele fica quieto, sozinho e tímido. O eu lírico diz que é um poeta em projeto, pois ainda é um adolescente, só tem quinze anos e agora que começou a escrever alguns versos. O poema terá valido a pena se o diálogo quebrar a indiferença, ou seja, se ocorrer um diálogo, uma interação entre o poema e o leitor. Eu também sou cheio(a) sonhos e medos, como, por exemplo, meu sonho é realizar-me profissionalmente e o meu maior medo é de perder as pessoas que amo. Assim como o João tem os ouvidos atentos, os meus são atentos para qualquer barulho, como a música, conversas, entre outros. Acho que quando poeta enfrenta o desconhecido ele se comporta com timidez, quando ele encontra pessoas diferentes, quando tem medo de alguma coisa, ele fica quieto e utiliza 


\begin{tabular}{|l|l|}
\hline alguma coisa, ele fica quieto e utiliza & uma metáfora no poema para mostrar \\
uma metáfora no poema para & isso. Eu já me senti um poeta em \\
mostrar isso. 22. Eu já me senti um & algum momento da minha vida, pois \\
poeta em algum momento da minha & a poesia é algo mágico, que nos faz \\
vida, pois a poesia é algo mágico, & usar a imaginação e "viajar" para \\
que nos faz usar a imaginação e & qualquer lugar, através da escrita e da \\
"viajar" para qualquer lugar, através & imaginação. Se eu fosse escrever uma \\
da escrita e da imaginação. 23. Se eu & autoapresentação minha, escreveria \\
fosse escrever uma autoapresentação & as minhas principais características \\
minha, escreveria as minhas & como, sou baixinha, tenho cabelos \\
principais características como, sou & escuros e ondulados, sou alegre, \\
baixinha, tenho cabelos escuros e e \\
ondulados, sou alegre, tenho vários \\
tenho vários sonhos e procuro \\
sonhos e procuro alcançá-los.
\end{tabular}

\section{Fonte: Os autores,}

A versão final, após trabalhado o texto, é apresentada no Excerto 3.

\section{Excerto 3. Versão final.}

O texto trata do poeta João, que descreve a si mesmo por meio de uma breve apresentação, de como ele é e o que ele tem. Segundo o narrador, ele é tocado tanto pelas cores da natureza quanto pelos olhos das garotas porque aprecia muito a natureza, as cores e a vida. Ele se compara a um grilo, pois, quando está com os íntimos ou escrevendo, ele é falante e elétrico; não para, assim como o grilo. Além disso, compara o poeta a um cara-de-pau, pois o poeta na hora da escrita escreve o que bem quer, não tem vergonha de se expor, se expressa de toda forma e nem se preocupa em esconder alguma coisa. O narrador não acredita já estar preparado como poeta porque ele afirma que está em projeto, ou seja, ainda está em formação para tornar-se um grande poeta. $O$ narrador estabelece a relação entre os elementos da natureza e os olhos das garotas, porque os olhos são tão belos quanto a natureza em si, e também porque ele aprecia muito a natureza, as cores e a vida. Ele fica atento à sonoridade das mulheres, porque está na adolescência $e$ é a fase em que começa a olhar diferente para as meninas, então é algo que chama a atenção dele. Com os íntimos o narrador é falante, porque se sente mais à vontade para conversar, e quando o poeta enfrenta o desconhecido se torna um caracol em sua casca-casa, porque ele fica quieto, sozinho e tímido. $O$ eu lírico diz que é um poeta em projeto, pois ainda é um adolescente, só 
tem 15 anos e agora que começou a escrever alguns versos. O poema terá valido a pena se o diálogo quebrar a indiferença, ou seja, se ocorrer um diálogo, uma interação entre o poema e o leitor. Eu também sou cheio(a) de sonhos e medos, como, por exemplo, meu sonho é realizar-me profissionalmente e o meu maior medo é perder as pessoas que amo. Assim como o João tem os ouvidos atentos, os meus são atentos para qualquer barulho, como a música, conversas, entre outros. Acho que quando o poeta enfrenta o desconhecido ele se comporta com timidez, quando ele encontra pessoas diferentes, quando tem medo de alguma coisa, ele fica quieto e utiliza uma metáfora no poema para mostrar isso. Eu já me senti um poeta em algum momento da minha vida, pois a poesia é algo mágico, que nos faz usar a imaginação e "viajar" para qualquer lugar através da escrita e da imaginação. Se eu fosse escrever uma autoapresentação minha, escreveria as minhas principais características, como: sou baixinha, tenho cabelos escuros e ondulados, sou alegre, tenho vários sonhos e procuro alcançá-los.

Fonte: Os autores

Verifica-se, assim, que a leitura e a escrita apresentam etapas, sendo relevante o uso de estratégias para os alunos a fim de que se apropriem das palavras alheias.

\section{Considerações finais}

Uma das estratégias de avaliação de leitura empregadas em sala de aula são as perguntas de leitura. Conforme a concepção de leitura que respalda o trabalho metodológico do professor, é possível constatar alterações na forma como o processo de leitura é realizado.

Sendo assim, este texto destacou as concepções de leitura e, para cada uma delas, foram propostas perguntas de leitura com o intuito de exemplificá-las. Na leitura como interação verifica-se o diálogo entre as concepções com foco no autor, no texto e no leitor, evidenciando que coexistem no processo de ensino e de aprendizagem da leitura. As perguntas com foco na interação - textual, inferencial e interpretativa, especificamente - seguem uma sequenciação, pois é necessário que o aluno, primeiramente, saiba trabalhar com o texto para depois estalebeler relações entre o que leu e seus conhecimentos prévios, inferindo informações para que, ao final do processo, ele seja capaz de interpretar, de produzir sentidos próprios. 
Com base na proposta, fundamentada nos estudos de Menegassi (2010b), verifica-se que o estudante, ao responder às perguntas para o gênero, constitui sua leitura de modo processual, pois extrai significados do texto e atribui sentidos ao que lê; posiciona-se diante da temática abordada; realiza inferências e produz sentidos; elabora um texto como contrapalavra.

Diante do exposto, a ordenação e a sequenciação das perguntas são recursos que possibilitam o desenvolvimento do aluno-leitor, pois orientam sua aprendizagem (MENEGASSI, 2008, p. 46). No entanto, ressalta-se que o trabalho com as questões "deve integrar o processo de desenvolvimento do leitor na escola, não podendo ser tomado como estratégia permanente de trabalho com o texto" (MENEGASSI, 2016, p. 43).

\section{Referências}

ANGELO, C. M. P. Mediações colaborativas e pedagógicas na sala de apoio à aprendizagem de língua portuguesa. 2015. 391f. Tese (Doutorado) - Programa de Pós-Graduação em Letras, Universidade Estadual de Maringá, Maringá, 2015.

BAKHTIN, M. M. Os gêneros do discurso. Estética da criação verbal. Tradução do russo por Paulo Bezerra. 4. ed. São Paulo: Martins Fontes, 2003 [1979].

; VOLOCHINOV, V. N. Marxismo e filosofia da linguagem: problemas fundamentais do método sociológico na ciência da linguagem. Tradução do francês por Michel Lahud e Yara Frateschi Vieira. 9. ed. São Paulo: Hucitec, 1992 [1929].

BRASIL, S. E. F. Parâmetros curriculares nacionais de língua portuguesa. Terceiro e quarto ciclos do Ensino Fundamental. Brasília: MEC/SEF, 1998.

CEREJA, W. R; MAGALHÃES, T. C. Português: linguagens, $6^{\circ}$ ao $9^{\circ}$ ano: língua portuguesa. 7. ed. São Paulo: Saraiva, 2012. 
COLOMER, T.; CAMPS, A. A avaliação da leitura. In: COLOMER, T.; CAMPS, A.. Ensinar a ler, ensinar a compreender. Porto Alegre: Artmed, 2002. p. 171-190.

DELL'ISOLA, R. L. P. A interação sujeito-linguagem em leitura. In: MAGALHÃES, I. (Org.). As múltiplas faces da linguagem. Brasília: UnB, 1996. p. 69-75.

FUZA, A. F.; MENEGASSI, R. J. Perguntas de leitura e o princípio temático em crônica: proposta de ordenação e sequenciação. Calidoscópio, v. 16, n. 1, p. 33-47, jan./abr. 2018.

FUZA, A. F. Proposta teórico-metodológica de ordenação $e$ sequenciação de perguntas de leitura a partir do princípio temático. Maringá, PR. Relatório Final de Estágio Pós-Doutoral. Universidade Estadual de Maringá, 85 p., 2017.

FUZA, A. F.; MENEGASSI, R. J. Ordenação e sequenciação de perguntas na leitura do gênero discursivo panfleto institucional. Diálogo das Letras, Pau dos Ferros, v. 06, n. 01, p. 259-286, jan./jun. 2017.

FUZA, A. F.; OHUSCHI, M. C. G.; MENEGASSI, R. J. Concepções de linguagem e o ensino da leitura em língua materna. Linguagem \& Ensino, Pelotas, v. 14, n. 2, p. 479-501, jul./dez. 2011.

FUZA, A. F. O conceito de leitura da Prova Brasil. 2010. $113 \mathrm{f}$. Dissertação (Mestrado em Letras) - Departamenteo de Letras, Universidade Estadual de Maringá, Maringá, 2010.

KLEIMAN, A. Oficina de leitura: teoria e prática. Campinas: Pontes, 1996.

LEFFA, V. J. Conceito de leitura. Porto Alegre: Sagra DC Luzzatto, 1996.

MARCUSCHI, L. A. Produção textual, análise de gêneros $e$ compreensão. São Paulo: Parábola, 2008. 
Ordenação e sequenciação de perguntas de leitura...

MENEGASSI, R. J.; ANGELO, C. M. P. Conceitos de leitura. In: MENEGASSI, R. J. (Org.). Leitura e ensino. 2. ed. Maringá: Eduem, 2010. p. 15-40.

MENEGASSI, R. J. Ordenação e sequenciação de perguntas na aula de leitura. In: YAEGASHI, S. F. R. et al. (Orgs.). Psicopedagogia: reflexões sobre práticas educacionais em espaços escolares e nãoescolares. Curitiba: CRV, 2016, p. 41-60.

MENEGASSI, R. J. Produção, ordenação e sequenciação de perguntas na avaliação de leitura. In: CENTURION, R.; CRUZ, M.; BATISTA, I. M. (Orgs.). Linguagem e(m) interação - línguas, literaturas e educação. Cáceres-MT: Ed. Unemat, 2011. p. 17-35.

MENEGASSI, R. J. Avaliação de leitura. In: MENEGASSI, R. J. (Org.). Leitura e ensino. Maringá: Eduem, 2010a. p. 99-120.

MENEGASSI, R. J. Perguntas de leitura. In: MENEGASSI, R. J. (Org.) Leitura e ensino. 2. ed. Maringá: Eduem, 2010b. p. 167-189.

MENEGASSI, R. J. O leitor e o processo de leitura. In: GRECO, E. A.; GUIMARÃES, T. B. (Orgs.) Leitura: aspectos teóricos e práticos. Maringá: Eduem, 2010c. p. 35-59.

MENEGASSI, R. J. Práticas de avaliação de leitura e a formação do leitor: reconstruindo conceitos no professor. In: ZOZZOLI. R. M. D. (org). Leitura. Revista do programa de pós-graduação em Letras e Linguistica AL - Maceió, n. 42, jul./dez.o 2008, p. 35-65. (subtítulo: Ensino de Língua Portuguesa).

MENEGASSI, R. J. Compreensão e interpretação no processo de leitura: noções básicas ao professor. Revista UNIMAR, Maringá, v.17, n.1, p. 85-94, 1995.

RODRIGUES, A. Perguntas de leitura e construção de sentidos: experiência com o $6^{-}$ano do Ensino Fundamental. 2013. Dissertação (Mestrado em Letras) - Programa de Pós-Graduação em Letras, 
Rayllane Cruz, Ângela Fuza e Renilson Menegassi

Universidade Estadual de Maringá, Maringá, 2013. Disponível em: <http://www.ple.uem.br/defesas/def_adelia_aparecida_pereira_da_silv a_rodrigues.htm>. Acesso em: 10 out. 2016.

SOLÉ, I. Estratégias de leitura. Trad.: Claudia Schilling. Porto Alegre: Ed. Artmed, 1998.

Recebido em: 16/07/2018 Aceito em: 15/11/2018

Title: Ordering and sequencing questions for the reading of the speech genre "poem" in middle school 